J. Linguistics 56 (2020), 865-891. C The Author(s), 2020.

Published by Cambridge University Press. This is an Open Access article, distributed under the terms of the Creative Commons Attribution licence (http://creativecommons.org/licenses/by/4.0/), which permits unrestricted re-use, distribution, and reproduction in any medium, provided the original work is properly cited.

doi: $10.1017 / \mathrm{S} 0022226720000316$

LOOKING B ACK, MOVING FORW ARD

\title{
On the nature of the lexicon: The status of rich lexical meanings ${ }^{1}$
}

LOTTE HOGEWEG

Radboud University

AGUSTIN VICENTE

Research Centre Micaela Portilla

(Received 14 January 2019; revised 14 July 2020)

Both in linguistics and in psycholinguistics there is some debate about how rich or thin lexico-semantic representations are. Traditionally, in formal semantics but also in philosophy of language as well as in cognitive pragmatics, lexical meanings have been thought to be simple stable denotations or functions. In this paper, we present and discuss a number of interpretational phenomena of which the analysis proposed in the literature makes crucial use of rich meanings. The phenomena in question are cases where the assignment of truthconditional contents to utterances seems to follow rules that do not operate on simple stable denotations or any other kind of 'thin' meanings but where composition takes rich structured representations as input. We also discuss problems for such accounts, which are mostly based on the inability of extant rich meanings accounts to explain many other interpretational phenomena, and we discuss the solutions that have been proposed to solve them. Furthermore, we address the discussion whether the informationally rich meanings are part of semantics, and more specifically part of the lexicon, or whether this information should be ascribed to more general world knowledge.

Keywords: lexical semantics, polysemy, coercion, rich versus thin meanings, semantic versus conceptual knowledge

[1] This research has been partially supported by Projects PROLE (PGC2018-093464-BI00) funded by the Ministry of Science, Innovation and Universities (MiCIU)/the Spanish Research Agency (AEI) and the European Regional Development Fund (FEDER, UE), by the IT1396-19 Research Group (Basque Government), and GIU18/221 (University of the Basque Country, UPV/EHU), which is gratefully acknowledged. Furthermore, the authors would like to thank Marina Ortega, Bryan Lefferman, Katie Fraser, Elena Castroviejo, Javier Ormazabal and the audience at the Concepts and Explanation Conference (Düsseldorf). Finally, we would like to thank three anonymous Journal of Linguistics referees for their helpful and constructive comments and suggestions. Both authors contributed equally to the article and are listed alphabetically. 


\section{INTRODUCTION}

Both in linguistics and in psycholinguistics there is some debate about how rich or thin lexico-semantic representations are. For example, is the lexical meaning of a noun like book an unstructured, abstract entity or does it consists of more or less detailed information about what books are, such as that they are (typically) used for reading? Traditionally, in formal semantics but also in philosophy of language as well as in cognitive pragmatics, lexical meanings have been thought to be simple stable denotations or functions. As McNally (2005) argues, formal semanticists have traditionally worked with such relatively impoverished lexical meaning representations for two reasons. The first is that they were mostly interested in the compositional behaviour of words on a more general level rather than with the more detailed and fine-grained aspects of their interpretation. The second reason is that formal semanticists have tended to maintain a sharp distinction between semantic and conceptual knowledge, leaving many interpretative problems to the so-called pragmatics waste basket. Pragmaticians of a cognitive persuasion, such as Relevance theorists (Sperber \& Wilson 1995, Carston 2002) or Recanati (2004, 2010), have taken issue with just one tenet of traditional semantics, namely, whether the output of semantic composition, understood in the way formal semantics understands it, yields truth-evaluable units. On their view, semantics underdetermines truth conditions (Carston 2002). However, until very recently (e.g. Carston 2012) the prevailing view in cognitive pragmatics has also been that semantics is basically denotational.

Not all authors have concurred with this way of seeing things. On the one hand, there are those who have tried to do semantics using richer lexical meanings. Thus, most Cognitive linguists take meanings to be conceptual and rich (see Evans 2009, for an exception). Jackendoff's (1992) Conceptual Semantics and Pustejovsky's (1995) Generative Lexicon are also examples of rich meanings approaches. On the other hand, other authors have taken the view that lexical meanings contain very sparse information. For instance, some linguists think that the semantics of verbs only includes abstract information related to their grammatical behaviour (Levin \& Rappaport Hovav 2011). Thus, the meanings of verbs like break, which typically take as arguments a cause and a patient, and which enter into the causative alternation, are said to only encode the information that they are change-of-state causative verbs. The meaning of break, according to this view, can be captured in the schema: [CAUSE [BECOME [BROKEN]]]. Such a schematic meaning suffices to account for the argument structure of break, as well as for its behaviour in alternations. Semantic features of other classes of words, such as nouns and adjectives, can also account for other grammatical features of the sentences in which they appear (e.g. Differential object marking (DOM) in languages like Spanish, where nouns which have a feature like +PERSON will appear preceded by $a$ 'to' in transitive and other constructions, e.g. Juan vio a María 'Juan saw María').

Not all authors in this thin semantics camp, however, believe that semantics is only in the business of accounting for grammatical behaviour. Their arguments 
have to do more with the attested variability in what a word can stand for (see Pietroski 2005, 2017; Travis 2008; Carston 2012). What variability suggests is that, in general, word (standing) meanings only put some constraints on what the word can be used to mean. For instance, according to Travis ' $[w]$ hat words mean plays a role in fixing when they would be true; but not an exhaustive one' (Travis 1996: 451). It is far from clear what the constraints that these authors identify with word meanings can consist in. A 'classical' view, such as Bierwisch \& Schreuder (1992) explains them in terms of necessary conditions, but many examples show that it is difficult to find necessary conditions of application of a term (see Wittgenstein 1953 on game).

In this paper we present and discuss a number of interpretational phenomena of which the analysis proposed in the literature makes crucial use of rich (lexical) meanings. The phenomena in question are cases where the assignment of truthconditional contents (or meanings, in general) to utterances seems to follow rules that do not operate on simple stable denotations or any other kind of 'thin' meanings. For example, when interpreting utterances containing the word book, information about books (e.g. that they are typically used for reading) may be relevant in determining the truth conditions of such utterances. That is, the meaning of wholes does not seem to reflect speaker's meaning, but compositional semantic meaning, where composition takes rich structured representations as input.

We will also consider alternatives to this prima facie description of the phenomena, addressing the question whether such representations are part of semantics, and more specifically part of the lexicon, or whether this information should be ascribed to more general world knowledge. In Section 2, we leave this question relatively open, although in presenting the phenomena we follow the account provided by the various authors, which usually entails a lexicalist or semantic view. In Section 3, we discuss problems for such accounts, which are mostly based on the inability of extant rich meanings accounts to explain many other interpretational phenomena, and we discuss the solutions that have been proposed to solve them. We also address the question of what the semantic/world knowledge distinction precisely means and what arguments are available for a lexicalist or a world knowledge view in the light of the previous discussions. As far as we can see, the arguments for favoring one view or another are not decisive at this stage in the debate, although we think that there is reason to doubt a certain 'thin' construal of lexical meanings.

\section{ON REASONS TO ADOPT RICH REPRESENTATIONS AS PART OF COMPOSITIONAL} PROCESSES

Various authors in linguistics, formal semantics, philosophy of language and computational linguistics have (partly independently, that is, without reference to each other's work) argued that certain linguistic phenomena can only be explained if we assume the availability of a certain amount of semantic information, typically assumed to be stored in the lexicon. Below we discuss the most important of these studies according to the type of phenomenon they address. 


\subsection{Coercion effects}

For a very long time, theoretical linguistics has been exploring the coercion effects occurring at different levels. Coercion is a repairing process that is triggered when there is some mismatch between the selectional restrictions or preferences of a linguistic item and the semantic properties of the element it has to compose with. Some authors (e.g. Jackendoff 2002) call the mechanism co-composition, trying to capture the idea that each party in the compositional process may have to adapt to the requirements of the other. Typical cases of coercion involve aspectual properties of verbs (e.g. iterative readings of verbs induced by the presence of 'for x minutes/ hours', as in Sarah could jump for hours). Here we will focus on two other kinds of coercion effects amply discussed in the literature: meaning/denotational shifts affecting individual lexical items and logical metonymy.

\subsubsection{Meaning shifts}

Classical cases of meaning shifts are:

(1) The ham sandwich wants the bill.

(2) John drank the bottle.

In (1), ham sandwich is interpreted as 'the customer who ordered the ham sandwich', while in (2) bottle is interpreted as 'liquid in the bottle'. What triggers such meaning shifts? The case of ham sandwich is more or less clear, and in principle does not need rich representations. Basically: the VP wants the bill requires an agent as an external argument, which forces the reader to reinterpret ham sandwich as referring to some agent. Yet, arriving at the interpretation 'customer who ordered the ham sandwich' requires that the hearer know that ham sandwiches are edibles, that they can be served at restaurants, and that they can be ordered by customers. That is, while the type-mismatch arises at some very basic level, effective repair involves accessing a representation rich in information. The case of bottle is similar, but more interesting for our purposes, since the semantic mismatch itself arises at a finer-grained level: drink selects for a drinkable, which arguably is of a finer-grained semantic type than abstract features or types such as +AGENT or +MASS. Then, to be able to solve the mismatch and reconceptualize bottle as a drinkable, the hearer has to know that bottles are containers that contain drinkables, which is more basic knowledge than the knowledge required to coerce the meaning of ham sandwich into 'ham sandwich orderer'.

Asher $(2011,2015)$ explains these cases of coercion using a rich and fine-grained type-theory, which has types such as 'food', 'container', 'animal', etc., such that a noun such as bottle is of the general type 'physical object', subtype 'container', etc. This kind of type theory, and others such as Modern Type Theory (Chatzikyriakidis \& Luo 2017), implement a rich meanings account by ascribing a hierarchy of types to linguistic items. However, independently of how one represents the semantic information contained in lexical entries, whether in terms of types or in terms of features, 
for example, the upshot is that many cases of coercion (mismatches and repairs) seem difficult to explain without rich representations.

The few empirical studies done on this kind of coercion effects point in the direction taken by a rich meanings account. Thus, Schumacher (2013) analysed, using event-related potentials, the differences between processing a sentence such as John put the beer on the table and processing a sentence such as John drank the whole bottle. According to Schumacher's results, 'beer' cases show no differences in the processing profiles of content and container usages (drink the beer vs. put the beer on the table), while 'bottle' cases exert additional computational demands (late positivities) when bottle refers to the content (drink the bottle). These results show that the underlying operations are different in each case. In the 'bottle' case, accessing the 'drinkable' or 'content' meaning seems to involve a proper meaning shift, whereas in the 'beer' case, readers access the 'container' meaning without difficulty. Schumacher refers to the operation that takes place in the 'bottle' cases as 'reconceptualization': a bottle, which is initially conceptualized as a physical object, subtype: container, has to be conceptualized as a drinkable. Thus, evidence shows that language users do perceive a semantic mismatch and proceed to repair it. Both the clash and the consequent repair involve accessing basic conceptual knowledge.

Frisson \& Frazer (2005) point in the same direction. They observed that switching from mass to count terms, in particular from container to contents ('beer' cases), was easier than switching from count to mass terms (rabbit-animal to rabbit-mass). While they argue that their results show that in both cases there is an operation that takes a literal meaning as input and delivers a modified meaning as output, the cost involved in switching from mass to count was considerably less, and comparable to what Schumacher has observed. The easiness of the switch in content-to-container cases can be explained if we assume that a beer is a drinkable, which, as such, requires a container. As we will see below, switches between senses that are in these 'requirement' relations are typically smooth. In any case, the difference between one sort of cases and the other seems to have to do with fine-grained features, such as 'container', 'drinkable', and so on. Such fine-grained features allow us to explain the mechanisms of the switch as well as why the switch is more costly in some cases than in others; for example, in count to mass switches in general, the processor finds a feature mismatch that has to be repaired by reconceptualization, while in content to container switches the sense 'container' is so easily accessed from the 'drinkable' sense that no actual reconceptualization is needed (more on this below, Section 2.6.2).

\subsubsection{Logical metonymy}

The much studied phenomenon of logical metonymy is a particular case of coercion, where the meaning of a noun is shifted into an event associated with the noun. A typical example is:

(3) Sarah began the book. 
Begin is an aspectual verb that requires an eventive predicate. Yet, the internal argument in (3) is a non-eventive noun. So the reader or hearer has to look for an event to meet the argument requirements of the verb. According to some underspecificity views (de Almeida \& Dwivedi 2008), begin comes with an unpronounced indexical element that has to be saturated. However, empirical evidence by and large seems to show that hearers and readers have to do some repair (see Zarcone 2014 for an overview). What is more controversial is how the repair is done. Pustejovsky (1995) proposed that repair is a language internal affair. Nouns have an associated qualia structure, and one quale informs about the function of the object the noun denotes (another quale, the agentive one, informs about how the object denoted by the noun comes into being). In the case of book, the 'telic' quale tells us that books are for reading. Typically, thus, the mismatch is solved by accessing this piece of lexical information and turning the meaning of began the book into 'began reading the book', although the mismatch can also be solved by accessing the agentive quale, which would yield the meaning 'began writing the book'. Zarcone (2014) suggests that hearers and readers are quite flexible with respect to the eventive predicate, as long as it is compatible with our world knowledge of the object that is said to be begun, such that begin the book could also mean 'begin proofreading the book', for instance (if the subject is a proofreader). The difference between a Pustejovskyan view and an approach such as Zarcone's boils down to a dispute about how much of world knowledge we access in solving the mismatch.

\subsection{Non-homogenous predication}

The next phenomenon for which a rich meaning solution has been proposed is the observation that predicates do not seem to attach to just one entity, but rather to 'facets' (Cruse 2004a, b) or aspects of such an entity. For instance, beautiful, when predicated of a car is an adjective that typically says something about the car as a physical object, while fast or broken, as well as good, relate to the function of the car. In particular, good predication (in artefacts) is typically predication of the functional aspect of an artefact: good knife, good book, etc.

To explain the different ways in which an adjective (or in fact, any predicate) can modify a noun, Pustejovsky (1995), following Moravcsik's (1975) rendition of Aristotle's four causes, introduced the idea of the above-mentioned qualia structures. Qualia structures try to capture what a thing is by telling what kind of thing it is (formal quale), how it came into being (agentive quale), what it is for (telic quale), and what it is made of (constitutive quale). Through a mechanism called selective binding, an adjective can apply to any of these qualia. Thus, good usually applies to the telic quale of the nominal, fast can apply to the telic or the agentive quale, wooden to the constitutive quale, etc.

McNally (2005) adopts the ideas of Pustejovsky and argues that formal semanticists should consider the possibility of rich qualia-structure style representations more seriously. McNally argues that (a version of) Pusetjovsky's qualia structures 
are also able to explain data that were not initially considered by Puetsjovsky, such as relational adjectives. Relational adjectives such as computational in computational linguist, are adjectives that are derived from nouns (synchronically or diachronically) and that typically introduce a relation between an individual of the sort described by the modified noun and an individual of the sort described by the nominal stem of the adjective. Previously, McNally \& Boleda (2004) argued that nouns have a kind argument and that relational adjectives denote properties of kinds rather than individuals. McNally (2005) proposes that this analysis can be seen as the adjective modifying the kind variable in the formal quale through selective binding. As such, McNally argues that this (and other examples) shows that rich, structured, qualia-style representations allow for the use of a single compositional strategy to account for a wide range of data.

\subsection{Multi-dimensional modifications: Privative adjectives and noun + denominalized adjectives}

The cases above involved predication modifying one dimension, within a range of different dimensions, of the meaning of a noun. In this subsection we look at cases where adjectival modification seems to affect several dimensions at the same time. Using the Pustejovskyan approach for the time being, one may say that many adjectives modify only the telic quale, or the agentive quale, or the constitutive quale, leaving the other qualia intact (see above). However, some adjectives have an overarching effect on the whole qualia structure.

For example, to make sense of a 'fake' compound (fake gun, fake Picasso) and of private adjectives in general, an interpreter has to change the denotation of the noun for another, non-intersective, denotation. However, this is not the only thing the interpreter has to do. Del Pinal (2015) adopts a Pustejovskyan framework, with the typical four qualia plus a further perceptual quale, which encodes stereotypical information about the appearance of the kind that the noun denotes. With that in place, he explains privative modification as an operation that maintains the perceptual quale but modifies the rest of the elements in the qualia structure (kind, origin, constitution, and, especially, telos, which is switched to the function 'being taken for an x', e.g. for 'being taken for a gun').

Stone lion cases, where we find a denominal adjective modifying a noun, can receive a similar treatment. A stone lion fits the stereotypical appearance of a lion. However, the rest of the features that compose the qualia structure associated with lion receive different values: most obviously, CONSTITUTION is stone-based, but the AGENTIVE, TELIC and FORMAL qualia are also affected by the adjectival modification. A stone lion is no longer an animal, its origins are man-made, and a telos (which natural kinds lack) is created. In principle, stone lion cases can also be accounted for by a process of widening of the extension of lion, triggered by a semantic mismatch (a violation of the Non Vacuity Principle), and then by applying the intersective adjective stone to the new extension. A similar treatment can be 
made of privative adjectives if privatives are understood as subsective adjectives (see Partee 2010). The issue with this kind of approach is whether it fully describes what goes on in the composition process. Stone-like modifiers have effects on denotations, but they also have systematic effects on several other dimensions in conceptual representations (dimensions that can then be targeted by predication). Insofar as we consider that semantics is in the business of explaining systematic compositional relationships between classes of words, it is advisable to take into account all the material that is systematically affected in composition. Working with thinner representations therefore only seem to provide a partial explanation of the complete phenomenon at issue.

Hogeweg (2019) empirically investigates the interpretation of adjective noun combinations such as stone lion. She relates the question of thin versus rich meanings (or in her terminology 'underspecified' versus 'overspecified' meanings) to the psycholinguistic phenomenon of suppression. Suppression is the process whereby semantic information that is initially activated is subsequently suppressed if it is disruptive in coming to a coherent interpretation of a word or phrase in context (but the precise nature and scope of the mechanism of suppression are under debate; see Giora 2008 for a discussion). While this phenomenon is not originally linked to the rich-thin debate (at least not as discussed in this paper), Hogeweg argues that suppression in general speaks against thin meaning accounts such as proposed by Bierwisch \& Schreuder (1992) and Blutner (1998, 2004), in which conceptual specification is based on an initial well-formed underspecified (or thin) semantic representation of the words combined. More specifically, she argues that such a thin account would not predict suppression (nor the initial activation) of conceptual features that are compatible with lion but not with stone lion (such as 'roars') (see also Hogeweg 2012). While Hogeweg finds the initial activation, she does not find evidence for suppression. While the results are basically indecisive (as the absence of evidence for suppression cannot be taken as evidence for its absence), Hogeweg argues that the initial activation does speak against a thin approach in which conceptual specification is restricted by an initial well-formed semantic structure. If it is assumed that conceptual enrichment takes place after the underspecified semantic representations have been combined to a semantically well-formed whole, features that are possessed by a lion but not by a stone lion (such as 'roars') would not be activated and consequently need not be suppressed.

\section{4 'Wild' truth-conditional variations}

By 'wild' truth-conditional variations we refer here mostly to the so-called 'Travis cases' (Travis 2008). Travis, like many other authors lately, believes that a compositional, truth-conditional semantics is a chimera. Travis' view is particularly radical in that it considers that truth conditions are occasion-sensitive, i.e. they depend on factors that cannot be regimented. Word meanings put some constraints on how words can be used, but, by and large, words can be used in many different 
and sometimes surprising ways. To prove his point, Travis has introduced in the literature many examples of sentences whose truth conditions vary in apparently non-systematic ways depending on the situation. His most discussed example is known as 'the green leaves case', where The leaves are green is judged to be true just if the leaves look green (because they have been painted green) in one occasion, but not in another, when the interest is in naturally green leaves (Travis 1996). There have been attempts at showing that this paradigmatic example of truth-conditional variation belongs within a predictable and systematic pattern of variations. Of special interest to us are approaches that resort to rich (lexical) representations such as Del Pinal's (2017) and Vicente (2012, 2015).

Del Pinal deals with this kind of Travis cases using his rich qualia structures mentioned above. According to his view, a colour predicate such as green can modify either the constitution quale or the perceptual quale in the lexical entry of leaf. If the former, then the leaf is understood to be green intrinsically; if the latter, the leaf is understood to be green as it appears to us. McNally \& Boleda (2017) show some sympathy for this kind of treatment, although they notice that any such approach also has to take into account the variability associated with when we judge that a certain object has a certain colour (e.g. red apple which is red on the outside vs. red watermelon which is red on the inside; see below).

Vicente's approach to the 'green leaves' case has obvious similarities with Del Pinal's, although his approach resorts to proposals in the concepts literature (e.g. Murphy 2002) and not to (enriched) qualia structures. According to the concepts literature, objects belonging to kinds can be conceptualized in terms of their nature/ essence or in terms of their prototypical appearance. Dobermans have pointy ears can be taken to be true if one thinks about Dobermans as they look, but will be taken to be false if one thinks about Dobermans as they (intrinsically) are (since their ears are floppy originally). In general, there are two ways in which a certain object can have a property: intrinsically or superficially. The green leaves case exemplifies a systematic and predictable ambiguity that can be expressed as follows (Vicente 2015: 64):

If we have an object $\mathrm{O}$ of kind $\mathrm{K}$, and a property $\mathrm{P}$ which is causally linked to the essence that $\mathrm{O}$ has in virtue of being a $\mathrm{K}$, then 'Det $\mathrm{K}$ is $\mathrm{P}$ ' - where 'Det $\mathrm{K}$ ' refers to $\mathrm{O}-$ is ambiguous.

In this way, the green leaves example patterns together with examples such as this dog is dangerous (true because the dog is on a lead and becomes dangerous, but false because the dog is not intrinsically dangerous), or this building is awesome (false because it is dirty and spoiled, but true because just a little bit of cleaning and care would reveal how awesome it REALLY is).

These kinds of approaches shows that the allegedly wild truth-conditional variations may turn out to be systematic and explainable in terms of a compositional semantic system, at least insofar as the entries of nouns can offer different possibilities for modification. Travis cases are typically analysed using the indexical apparatus (see Rothchild \& Segal 2009, Hansen 2011). The indexicalist approach 
has some advantages but a crucial shortcoming. The main advantage is that by postulating a large set of indexes, one is able to cover a good number of variations in, for example, what colour adjectives denote. The crucial shortcoming is that the approach gets too specific about one kind of predicate and thereby misses some important generalizations. For instance, Hansen's (2011) detailed treatment of colour predicates postulates three different kinds of parameters that have to be adjusted to account for the full range of variability that colour predicates exhibit. This kind of move may solve the issue of the variability in colour predicates, but it does not explain what is common between colour predicates and other kinds of predicates in the way they can modify nominals. The main argument for adopting rich meanings thus is that we will not 'see' certain generalizations pertaining to kind terms + modifiers/predicates compounds if we do not adopt a rich approach to what nominals can contribute to compositional processes.

\subsection{Semantic (in)felicity}

Another recurrent argument for why thin or underspecified lexical semantic representations are problematic, is that they cannot explain why certain combinations of words are prima facie semantically infelicitous while others are not. This problem was also one of Pustejovsky main arguments for introducing the aforementioned qualia. Pustejovsky (1995) introduces the notion of semanticality, analogous to the notion grammaticality, which refers to the semantic well-formedness of expressions. One of the most important goals of lexical semantics, according to Pustejovsky, is to characterize the semanticality of natural language utterances. Sentences can be semantical to a certain degree, as illustrated by Pustejovsky with the examples in (4) (Pustejovsky 1995: 41):

(4) (a) Mary began the book.

(b) ?John began the dictionary.

(c) ??Mary began the rock.

The sentence in (4a) allows for two (default) interpretations, one in which Mary is involved in an activity of reading and one in which she is involved in an activity of writing (see above). Sentence (4b) does not allow the reading in which John is engaged in a reading activity. For (4c), there is no generally available reading at all, although one can be created in context (e.g. if Mary is a rock climber and the rock is a rock one can climb). According to Pustejovsky, such distinctions in interpretation are 'real, systematic and part of the language itself' (Pustejovsky 1995: 42). As explained above, one quale in Pustejovsky's qualia structure informs about the function of the object the noun denotes and another about how the object came into being. The differences between (4a), (4b) and (4c) in semanticality are then caused by our semantic knowledge of what books, rocks and dictionaries are, what you can do with and to them, and whether agents are involved in their coming into being, as represented in their associated qualia structures. 
McNally (2005) too aims to explain why certain combinations are semantically felicitous while others are not and argues that the answer lies in highly structured semantic representations. McNally addresses the combinability of gradable adjectives. In order to explain why a phrase like partially blue sand is fine while a phrase like partially blue beverage is questionable, adjectives like blue should have a scale structure imposing restrictions on the expressions it combines with. The adjective blue can be associated with two types of scales or dimensions, relating to the 'trueness' of the color (e.g. pale blue, very blue, dark blue) or to extension (relating to the parts of the entity described by the noun it combines with that are blue). The latter one is bounded (that is, it has endpoints) while the first one is probably not. The lexical entry for the modifier partially specifies that it combines with a closed scale, so when blue is combined with partially the scale of blue must be fixed as the extension scale. As such, the adjective phrase partially blue selects for nouns describing entities with discrete parts, for if an entity does not have discrete parts, it will be difficult to distinguish the parts which are blue from those which are not. ${ }^{2}$ So in order to explain why partially blue sand is felicitous while partially blue beverage is typically not, not only the properties of the adjective are relevant, but also the structure of the entity denoted by the noun. McNally proposes that this information is represented in the CONSTITUTIVE quale of the noun. ${ }^{3}$ McNally argues that without such detailed semantic information it is not only unclear how we would account for the interpretation of blue, but this information is also going to be of use in accounting for other semantic phenomena, such as the distribution of nouns that refer to portions of matter such as slice, grain, etc.

The argument relating to semantic infelicity has been made for verbs too. Goldschmidt (2018) analyses force verbs such as hit, stroke, push, and (amongst others) their compatibility with adverbs such as hard and lightly. Following the argument approach by McConnell-Ginet (1982), Goldschmidt argues that the fact that force verbs can be modified by such adverbs indicates they have a force component, as illustrated by the lexical entry for hit in (5) (Goldschmidt 2018: 94).

$$
\text { hit }=\lambda y . \lambda x . \lambda . e . \exists f[\operatorname{hit}(e) \wedge \operatorname{AGENT}(e, x) \wedge \operatorname{PATIENT}(e, y) \wedge \operatorname{FORCE}(e)=f]
$$

But this is not enough, as it does not explain why some combinations of force verbs and force adverbs are infelicitous. In particular, it provides no explanation for why some force verbs combine only, or at least easier, with adverbs indicating low force

[2] Note that McNally (2005) argues that not all bounded adjective phrases are sensitive to the part structure they modify. For example, awake can apply holistically to an object in different degrees. Therefore, McNally argues, 'we should impose the condition that an adjective phrase select only for nouns describing entities with discrete parts just in the case of adjectives that hold of an object in virtue of holding of one or more of its proper parts' (McNally 2005: 201).

[3] Note that McNally (2005) acknowledges that liquid and beverages CAN have parts but, she argues, at least in most normal circumstances they do not have identifiably discrete parts. Only in certain circumstances their parts can be discrete, for example when a cocktail consist of ingredients with different weights. McNally therefore proposes that the constitutive quale of nouns like liquid and beverage are actually unspecified with respect to whether their denotations have discrete parts or not. 
(such as lightly) than with adverbs indicating high force (such as hard). To explain this, Goldschmidt argues, force verbs must also be specified for the intensity of the force. ${ }^{4}$ The infelicity of a phrase like stroke hard can then be explained by a conflict of the lexically encoded intensity of the verb (low) and the intensity expressed by the adverb (high). Goldschmidt identifies more problems with the relatively basic, (Neo-)Davidsonian semantic representation of force verbs, for example that such basic representation of force verbs do not allow us to represent the meaning differences between the different force verbs. In order to solve the various shortcomings, Goldschmidt argues, the lexical entries of force verbs should, besides the information concerning intensity, also contain information about (amongst others) the direction of the force, and aspectual information.

\subsection{Polysemy and co-predication}

\subsubsection{Polysemy}

Research on the psycholinguistics of polysemy focuses on the processing and the representation of the different senses of polysemous expressions. Most authors reject the strongest version of the sense enumeration model, according to which the different senses of an expression are stored in different lexical entries. Such a view effectively blurs the distinction between polysemy and homonymy. However, in homonymy (e.g. bank), there is competition between meanings, such that when one is selected, the other is inhibited, and there is a strong bias towards the most frequent, or dominant, meaning. In contrast, in polysemy all the senses of a polysemous expression are still active after one of them has been selected, and the frequency effects observed for homonymy are much more attenuated, if present at all in polysemy. MacGregor, Bouwsema \& Klepousniotou (2015) put it thus: 'polysemous senses act collaboratively to strengthen the representation, facilitating maintenance, while the competitive nature of homonymous meanings leads to decay' (MacGregor et al. 2015: 1).

That the different senses of a polyseme tend to activate, instead of inhibit, each other is accepted by most parties in the debate. There is some disagreement concerning whether this is something that occurs with all sorts of sets of senses or only with those that are closely related (see Foraker \& Murphy 2012). There is also lack of agreement as to how to interpret the co-activation facts (i.e. in those cases where senses behave cooperatively). Within the psycholinguistics literature (e.g., Klepousniotou, Titone \& Romero 2008, Frisson 2009, Vicente \& Falkum 2017), the main two approaches to co-activation facts are:

(i) the semantic representation associated with a polysemous term is thin, be it some kind of abstract or core meaning that covers all the senses, or a bare node that links to the different senses; and

[4] This aspect is embedded in a detailed analysis of force in which insights from a non-force based vector model (Zwarts \& Winter 2000) are combined with force vectors in the sense of Wolff (2007). 
(ii) the semantic representation is rich, e.g. in the sense of, for example, a possibly structured representation that stores all the senses, from which speakers and hearers have to select.

However, outside the psycholinguistics literature, there are approaches that fall in between these two main contenders. For instance, in Conceptual Semantics, Jackendoff (1989) argued that the representation of a polysemous verb such as keep consists in a core component (e.g. CAUSE [ENDURANCE [STATE]]) plus a feature taken from a list of semantic fields that has to be specified in context (e.g. LOCATION, EMOTION, etc.). In Jackendoff's approach, selecting a specific sense of a polysemous verb is a constructive phenomenon involving two different kinds of representations, a core meaning and a list of semantic fields. However, in the light of what we know now about polysemy processing, a more plausible approach is that the 'missing' feature that completes the core component is stored in the lexical entry of keep. This is actually the way Zeevat et al. (2017) have proposed to deal with multiply polysemous verbs.

Zeevat et al. (2017) argue that the selection of meaning for polysemous words in use can be modelled by assuming that there are moderately universal semantic features and that word meanings are related to distributions over sets of such semantic features. ${ }^{5}$ These feature sets can be specified by a number of operations over the semantic features. For example, some features may be absolute, as they are always part of the interpretation of the word (like Jackendoff's core component), some features may be excluded, for some set of features it may hold that a forced choice has to made between them (comparable to the yet to be specified feature by Jackendoff, but the possible options are represented in the lexical entry of the word in Zeevat's et al. approach), etc.

Zeevat et al. illustrate the working of these operations by means of the verb fall. They identified 35 uses for fall in English (e.g. John fell, the light falls on the table, Christmas day falls on a Sunday this year) and 78 uses for this verb or its equivalent in English, Dutch, French, Russian and German combined. Zeevat et al. argue that by making use of the above-mentioned operations, all those 78 uses can be captured by one single rich meaning representation. This representation includes for example the information that the act of falling involves a theme and that a forced choice has to be made between the type of theme (e.g. a concrete object or person, light, a date). Furthermore, since falling is strongly correlated with a lack of intentionality with respect to its direct cause, a lack of control of the theme is an obligatory part of the meaning representation. It would take us too far to discuss the details of their

[5] As the distributions are based on the experience of the language learner or user (how often the feature combinations are expressed by a word), speakers will always have (slightly) different distributions for each particular word. Therefore, Zeevat et al. (2017) make use of equivalence classes of distributions. By using equivalence classes for $\leq, 0$ and 1 , intersubjective convergence with respect to a word $w$ can be explained by the speakers always agreeing that bundle $b$ is less probable than bundle $c$ in an interpretation of $w$, or that bundle $b$ always, or never, occurs in such interpretations. 
proposal (for example, to prevent overgeneralization a mechanism of blocking is built in) but Zeevat et al. argue that the structured and elaborate representations that they propose for fall (and its counterpart in other languages) can be used to model the interaction of polysemous words with the context, such that the context selects the appropriate set of features from an encompassing representation. This contrasts with a sense enumeration approach in which the possible interpretations are stored separately without reflecting the commonalities between them and leaving no room for novel combinations of features.

In the psycholinguistics literature it is often claimed that the empirical evidence concerning processing cannot distinguish between a thin and a rich approach to polysemy (Frisson 2009, MacGregor et al. 2015). However, there are other kinds of reasons that favor rich representations approaches. As has been said, thin lexical representations can be common cores or bare nodes. While the common core approach can work for polysemy generated via metaphor, it is doubtful that all the senses generated via metonymy can be captured by a common core represented by a list of features: there are few features shared by rabbit-the-animal and rabbitthe-fur, for example, or by school-the-process (I went to school) and school-thebuilding (The school needs to have the heating system fixed). Besides, if the meaning of a polyseme is represented as a common core, how can new senses, which are not captured by the core, be created (Carston 2016)? Each new sense would force us to either remove some features or include new features in the common core. For instance, new metaphorical uses of cut (as in cut the interest rates) would have the effect of removing features that have to do with applying cutting instruments to objects. Evaluative uses of sit as in A tricycle sat unattended across the street (Fraser 2018), apparently add a feature of 'idleness' to the eventual common core (while at the same time removing all the features that describe the posture of sitting). So while common cores could capture what is common to the different uses of a word at a given stage and in a particular speaker (if indeed there is something common to all such different uses), it is unclear what further role they can play in our linguistic capacities. On the other hand, it is not clear what we would gain by going even thinner and having as representations bare nodes that connect words with senses in our lexical entries. ${ }^{6}$ It looks like they are unnecessary intermediate stations lacking explanatory power.

In sum, theoretical (Pustejovsky 1995, Asher 2011) and empirical (Frisson 2009, 2015) considerations provided in the literature militate in favor of the onerepresentation approach to polysemy. While there are different ways to develop such an approach (see e.g. Carston 2019, for a 'polysemy complex' account), it seems that the thin meanings version of the approach is less explanatory and/or parsimonious than its rivals. This is a point that in principle holds generally, i.e. for all kinds of polysemies (though see Vicente 2018), but it is particularly valid for

[6] The same can be said about Pietroski's (2017) indexes that connect words and concepts. 
those polysemous words that pass co-predication tests, which are typically those whose senses are more closely related.

\subsubsection{Co-predication}

As said, probably the kind of polysemy whose explanation most obviously requires rich knowledge structures is what is called 'inherent polysemy' (Pustejovsky 1995) or 'logical polysemy' (Asher 2011). Unlike in most cases of polysemy - regular or irregular - where conjunction reduction gives rise to zeugmatic readings (e.g. Arthur and his driving license expired yesterday), this kind of polysemy is characterized by passing co-predication and anaphoric binding tests. Co-predication occurs when the same polysemous nominal expression has simultaneous predications selecting for two or more different meanings or senses. For instance:

(6) (a) The book is heavy and interesting.

(b) The school round the corner starts at 9:00 and has prohibited wearing hats in the classroom.

In (6a), heavy selects the meaning 'book-volume', while interesting selects the meaning 'book-content'. In (6b), the senses involved are: 'school-building', 'school-process', and 'school-institution'. Co-predication is a hot topic in Chomskyan thin semantics (Chomsky 2000, Collins 2017, Pietroski 2017) as the phenomenon allegedly shows that many nouns lack denotations (since no entity can be a building, a process, and an institution at the same time). If the meaning of a noun is not a denotation, the argument goes, it has to be a language-internal something that serves to connect words with concepts (Pietroski 2005, 2017). Thus, co-predication plays an important role in the debate between Chomskyans and defenders of truthconditional semantics, on the understanding that truth-conditional semantics is committed to defending that word-types have stable denotations that are simple entities. (A view that here we also treat as a variant of thin semantics.)

However, this kind of reaction to co-predication apparently ignores work done on the phenomenon in computational linguistics and in psycholinguistics. In computational linguistics, Pustejovsky (1995) introduced dot types in his type theory to account for co-predication. According to this approach, a noun such as book is of the type physical-object.dot.informational-content, because it is not of just one simple type. Books can have properties characteristic of physical objects, but also of informational contents, so they cannot belong to just one of these types. There is no agreement about the denotation of dot types. Asher (2011) holds that they are bare particulars that can be conceptualized in two or more different ways at the same time, while Gotham (2017) argues that they denote complex mereological compounds. In both cases, however, meanings of co-predicative nouns are taken to be rich, either conceptually (Asher) or ontologically (Gotham). In general, any account that concurs with the Pustejovskyan idea that there are dot types is committed to some variant of a rich meanings account for terms that allow for co-predication, as 
dot types are already complex types (which can be VERY complex in case like school).

Ortega-Andrés \& Vicente (2019) have recently offered a different approach to co-predication, inspired by the psycholinguistics research on polysemy mentioned above. They propose that the lexical meaning of a noun such as school is a conceptual structure that gives different possibilities for denotation. The different senses within the structure relate to entities that make school-the-institution real, and so the account applies, mutatis mutandis, to all institutional kinds. A co-predicative nominal, in their view, does not denote a dot object or a complex entity, but stands for various denotations/senses that receive a synchronous strong activation and can be accessed by interpreters when retrieval is mandated by the selectional preferences of the predicates. In contrast with mereological approaches, this view assumes that the richness of meanings does not affect denotations but conceptual representations (i.e. denotations are simple entities, but the lexical meaning of the polysemous word is a rich knowledge structure). Schumacher (2013) suggests a similar approach. According to her, some sense alternations are easier than others: content-to-container polysemies (e.g. beer) are easier than container-to-content polysemies (e.g. bottle; see above). This fact has consequences for co-predication: easy-to-process polysemies typically behave well in co-predicational settings (The beer is on the table and tastes bad by now), while polysemies that involve reconceptualization (see above) are typically more problematic (Mary drank the whole bottle and dropped it). According to Schumacher, groups of senses that allow for co-predication typically have references that are intimately related. This close relationship at the level of denotations explains why the activation of one of the senses involves a strong, stable and enduring activation of the others. In turn, stable and enduring co-activation explains how it is possible for interpreters to retrieve particular senses as they go on encountering predicates that select for them.

The idea that the different denotations of a co-predicational nominal have to be in some particularly close relationships is a recurring idea. For example, Deane (1988: 176-179) already held the view that logical polysemy (which he called 'open allosemy') was different from other kinds of polysemies in that the different senses of this kind of polysemes formed part of a coherent knowledge structure. Blutner (1995) also recognizes that the senses of these kinds of polysemes are connected in an intimate relation that defies the idea that they can be recruited via pragmatic means only. What gives coherence to the structure is that the denotations of the different senses are in some kind of realization relation (a school-building makes the institution real; a school-process makes the function of a school real, etc.; see Ortega-Andrés \& Vicente 2019, Vicente 2019, for development). So 'conceptualists' and 'mereologists' (see especially Arapinis \& Vieu 2015) agree that the different denotations of co-predicational nominals are in very special (metaphysical) relations. At present, only Liebesman \& Magidor (2017) have proposed an account of co-predication that does not resort to coherent knowledge structures or to complex entities. Their account has it that the reference of a noun such as book is 
context dependent and that any possible reference of a co-predicative noun can inherit properties from the other possible denotations. However, as it stands the approach lacks explanatory power. It still has to account for the clearly constrained variability in what book can refer to (which is of the same kind as in letter, document, etc.), as well as for the restrictions imposed on property inheritance, which are also systematic. Concerning this last point: the typical cases where we admit that an entity can inherit properties from another are cases where one of the entities CONSTITUTES the other (as in the case of a piece of marble that constitutes a statue; see Baker 2000 for the principles of property inheritance). Thus, the fact that co-predication suggests that there can be property inheritance between the different denotations of a word, suggests in turn that such different denotations are in relations that resemble constitution relations. Once this is acknowledged, the 'property inheritance view' will not differ much from other proposals on the market.

\section{THE PROBLEM OF INFLEXIBILITY AND THE WORLD KNOWLEDGE/SEMANTIC KNOWLEDGE DISTINCTION}

The proposals presented in the previous section share the view that (lexical) entries contain (or give access to) quite a lot of information. A recurrent problem that most of the accounts described in the last section have is that they do not account for the full range of possible interpretations that many of the examples that they make use of may have. This is a point that has been signaled by many different authors concerning Pustejovsky's Generative Lexicon (GL) approach (e.g. Blutner 1998, Fodor \& Lepore 1998, McNally \& Boleda 2004, Falkum 2011, Bücking \& Maienborn 2019). Yet, we may assume that this is not a problem that affects only the GL approach (see e.g. Asher 2015, for some corrections to Asher 2011). The issue we will deal with in this section is to what extent the information that has been proposed to play a role in the analysis of the phenomena discussed above (plus the information that would explain departures from predictions based on the GL) can be considered semantic information. In what follows, we will focus the discussion mainly on amendments to or rebuttals of the GL, since it is, by far, the most influential rich meanings account. We want to explore different reactions to the problem of inflexibility as it has arisen for the GL, as they are illustrative of the different positions one may take in the face not only of such problem but also in the face of the set of data presented in the last part of this section.

For instance, Pustejovsky's approach to logical metonymy has often been criticized for being too restrictive/inflexible. Fodor \& Lepore (1998) argue that many of the inferences Pustejovsky assumes (e.g. from 'want a cigarette' to 'want to smoke a cigarette') are defeasible. Relevance theorists such as Falkum (2011, 2015, 2017) have noted similar problems for many other phenomena: on the one hand, qualia structures often lack the relevant information to make the right predictions (e.g. words for animals lack a telic quale, but animals can be said to be good or bad); on the other hand their information is often too restrictive, leaving no room for exceptions (e.g. begin the book can mean 'begin binding the book' or, as mentioned 
before 'begin proofreading the book'). In broad lines, two types of adjustments have been proposed to deal with this problem. The first type of approach proposes that the answer lies in thinner lexical entries.

Bücking \& Maienborn (2019), for example, argue, much like Falkum (2011, $2015,2017)$, that qualia structures are indeed too poor to account for the whole range of possible interpretations. While fast in fast book is predicted as most likely to be interpreted as referring to a reading event accessible through the telic quale, in the right context, a fast book could also be understood as referring to a book that was illustrated or copy-edited fast. Furthermore, Bücking \& Maienborn argue, many pieces of knowledge that are also relevant for the interpretive flexibility of lexical items have no natural place in the qualia structures as proposed by Pustejovsky. For example, the most natural interpretation of fast dog is a dog that runs with high speed. Yet, running is not the telic role of dogs, that is, dogs are not made for running (see also Falkum 2011). Interestingly, Bücking \& Maienborn (2019: 3) conclude as follows:

By assuming qualia structures, Pustejovsky opens the lexicon and imports a small part of world knowledge into the lexical system — basically knowledge about how objects come into existence and what they are typically used for. But, as our short discussion of fast has already shown, far more world knowledge would actually be needed in order to account properly for the observed interpretive flexibility. However, if all this world knowledge were incorporated, the lexical system and the compositional machinery would be in danger of collapsing.

Bücking \& Maienborn also argue against a radical underspecification account such as proposed by Dölling (2003, 2005, 2014). In Dölling's analysis a predicate modifier such as fast triggers the insertion of a compositional operator that links the modifier's contribution to the target argument only indirectly through a new variable which is related to the target argument in a way that is semantically underspecified. As a result, adjective noun combinations like fast race (where the noun expresses an event) are treated similarly to adjective noun combinations like fast car (where the noun refers to an object). The specification of the underspecified semantic form is carried out in terms of pragmatic inferences based on world knowledge. Bücking \& Maienborn argue that an account of coercion by adnominal modification should indeed be flexible, in the sense that coercion can be triggered by the wider context, an argument that was also made by Dölling (2014) in favor of his underspecification approach. However, a proper analysis should also be able to account for the observation that coercion by adnominal modification is restricted in that the possibilities for coercion differ per lexical item; for example, while schnelle 'quick' in schnelle Pilzsuppe 'quick mushroom soup' can indicate that the soup was prepared in a short time, flinke 'nimble' in flinke Pilszuppe 'nimble mushroom soup' cannot likewise indicate that the soup was prepared in a nimble manner. Bücking \& Maienborn therefore argue that coercion should be rooted in the lexical system. 
They propose a formal and precise analysis building on Asher's (2011) Type Composition Logic in which information that explains the coercive potential of words is included in their lexical entries, such as the type requirements of a modifier's target which can be more or less specific. Other information that is needed to resolve the interpretative conflict, such as the default eventualities entities are related to, is captured by world knowledge, while the lexical entries specify the manner in which this knowledge may be integrated. As such, their proposal entails a kind of lexical semantic content which is thinner than qualia structures and which maintains a strict division between lexical and conceptual knowledge, while acknowledging that both types of knowledge are needed to resolve the interpretative conflicts discussed.

Blutner $(1998,2004)$ notices many of the same problems with a Pustejovskyan approach to lexical meanings. Unlike Bücking \& Maienborn's proposal, Blutner's solution is found completely outside of the lexicon. Blutner's proposal involves radically underspecified lexical meanings containing, for example, place holders and restrictions for individual and relational concepts, combined with a mechanism of pragmatic strengthening based on contextual and encyclopedic knowledge. This process of enrichment makes use of cost based abductions combined with a blocking mechanism based on a precise treatment of Atlas \& Levinson's (1981) Q- and I-principle. This explains, according to Blutner, why a phrase like The tractor is pumped up is infelicitous. To put it very simple, the anomaly results from the fact that those parts of tractors that may be pumped up (the tires) do not form a salient enough part of a tractor and therefore this interpretation can be blocked by specifications that refer to more salient parts, for example the coachwork. As the coachwork of a tractor forms a more salient part of a tractor, the abduction process will yield this as a less costly specification of the part of the tractor that is pumped up than the tires. However, specifying the coachwork as the part that is pumped up leads to sort conflicts (as the coach work of a tractor is not something that can be pumped up), as a result of which the utterance comes out as pragmatically anomalous (under plausible context conditions). The notion of salience itself, however, is explicitly described as non-representational and non-compositional and seems to be determined on an ad hoc basis.

The second type of solution to the identified problems with the GL does not assume thinner lexical entries but argues that the appropriate reaction towards exceptions to the proposed regularities is to make the lexicon even richer. Zarcone (e.g. 2014) shows empirically that hearers and readers are indeed quite flexible with respect to the eventive predicate in begin cases: as long as the predicate is compatible with our world knowledge concerning the object that is said to be begun, any eventive predicate can be acceptable. In her experiments, subjects did pause to find an event (i.e. coercion was evidenced), but there was no sign of a preference for coercion in one way or another. That is, subjects did not perceive any semantic anomaly if the event retrieved did not come from either the telic or the agentive qualia. As mentioned above, the difference between a Pustejovskyan view and the approach Zarcone proposes, boils down to a dispute about how much of 
world knowledge we access. Zarcone's idea is that coercion in logical metonymy activates a whole knowledge representation from which we retrieve the event that fits the context best, whereas Pustejovsky and followers believe that lexical meanings offer just two possibilities, thereby demarcating a line between lexicosemantic and conceptual knowledge. Thus, Zarcone's view implies enriching the lexicon to the point that it includes all the world knowledge related to a word.

A more nuanced reaction, though still in the line of enriching the lexicon, is McNally \& Boleda's (2017): McNally \& Boleda also argue that Pustejovsky's qualia-structure approach is too coarse grained to explain the full range of data when it comes to certain adjective noun combinations and that detailed conceptual knowledge is needed to arrive at the right interpretation of such combinations. For example, the constitutive quale of the noun apple may introduce the part of the apple that may be modified by red. However, this doesn't specify that it is typically the skin of the apple that is red, rather than for example its pulp. McNally \& Boleda argue that such interpretations arise from very detailed conceptual knowledge, 'presumably accessible from the words involved' (McNally \& Boleda 2017: 252) and consequently, that we need even richer and more nuanced lexical representations. McNally \& Boleda propose to model such rich representations by means of (compositional) distributional semantics, in which the semantics of words is represented as a function of the contexts (typically the surrounding words) it occurs in. McNally \& Boleda (2017: 259) argue that 'though crude and incomplete as an approximation of what concepts are [...], these representations have the advantage of being easy to construct and incorporable into a testable interpretive model'.

An important and innovative aspect of McNally \& Boleda's approach is that they make a clear distinction between default interpretations and interpretations in which composition depends on specific, independently available properties of the referent. In the latter case, almost any interpretation is possible. For example, red box could refer to a box which has a brown surface but which is known to contain red objects. McNally \& Boleda therefore argue that there are two types of modification: conceptually afforded composition that builds on rich conceptual information leading to a default interpretation (in which red box is interpreted as referring to a box which is red on the outside) on the one hand and referentially afforded composition on the other hand, in which the result of combining the modifier with the noun depends on specific properties of the previously introduced referent (due to which red box can refer to e.g. an already familiar brown box containing red objects).

Thus, McNally \& Boleda's approach tries to explain two phenomena: conceptually afforded composition explains default systematic patterns of combination of units into truth-conditional compounds; referentially afforded composition accounts for what seem to be idiosyncratic ways of construing truth-conditional meanings. As such they defuse the two most important arguments against rich lexical meanings as described above: that they are often too imprecise on the one hand and leave no room for exceptions on the other. 
The above shows that the responses to well known problems with Pustejovsky's account range from blurring the world knowledge/semantic knowledge divide to having very thin, underdetermined, lexical representations. An important point of contention underlying these different views is whether the information needed in the analysis of the several phenomena is used in the process of composition. McNally \& Boleda (2017) claim that detailed conceptual information, which, they assume, forms the input to compositional computation, is needed to account for, inter alia, adjective-noun combinations. What Bücking \& Maienborn's (2019) and Blutner's $(1998,2004)$ proposals have in common is that at least part of the information needed to explain several of the interpretative phenomena is noncompositional.

In Section 2 we showed that the analysis of many interpretational phenomena involves rich informational structures and, insofar as these structures play a role in the composition of the truth-conditional meaning of the various phrases, it is typically assumed that such structures form the lexical meaning of the words involved. This assumes that composition of truth-conditional meaning is a semantic affair. However, this assumption is contested by various authors. For instance, followers of Relevance Theory (e.g. Sperber \& Wilson 1995; Carston 2002, 2012) would say that the knowledge structures required to explain the data belong within encyclopedic entries attached to lexical items, so that all the phenomena we have described in the previous section are phenomena that pertain to concepts/world knowledge. The encoded meanings of lexical items that lead to these encyclopedic entries are of a different nature, usually described as atomic concepts (but see Carston 2012). Regarding composition, it may well take place at the conceptual level, i.e. it may well be a non-lexical process. Recanati (2010), for instance, holds that only modulated meanings enter into compositional processes. Lexical meanings can be stable denotations, underdetermined representations, or perhaps there are no such lexical meanings (a position known as semantic eliminativism). In any event, lexical meanings under any of these construals do not compose. Composition works only with concepts accessed in the interpretative process. As Del Pinal (2017) points out, the modulated meanings that Recanati speaks about may be aspects of bodies of knowledge that have a (enriched) qualia-like structure (see also Vicente 2019).

In this respect, there is some empirical evidence that indicates that world knowledge information indeed has a role in composition. Hagoort et al. (2004) combined EEG/fMRI studies that compared the unification of linguistic knowledge with the unification of world knowledge. Participants saw one of three versions of a sentence such as The Dutch trains are yellow/white/sour and very crowded where they consider it to be world knowledge about trains in Holland (which are typically yellow) that makes the second version of this sentence false, while, as they argue, it is a core semantic feature of the predicate sour that does not fit the semantic features of its argument the Dutch trains. For both violations, an N400 effect was observed, indicating that what is usually considered to be conceptual information plays a role 
in the compositional process. Based on this (Hagoort et al. 2004) and other studies, Hagoort, Baggio \& Willems (2009: 4) conclude:

As for compositionality, the results of the studies just reviewed may mean two things, depending on one's views on the lexicon. One possibility is that the lexicon includes declarative memory in its entirety, and then simple composition seems enough to account for the similarity between the N400 effects. Alternatively, the lexicon includes invariant (i.e. linguistic) meanings only, and then enriched composition-the thesis that the lexicon is not the only source of semantic content-seems necessary to explain the observed N400 effects (Baggio et al., in press [= Baggio, van Lambalgen \& Hagoort 2012 LH\&AV]).

While these results show that specific and detailed knowledge is indeed used during composition, the question remains, as the passage above indicates, whether this knowledge is part of the lexicon. It indeed seems difficult to separate lexical meaning from general conceptual knowledge if the goal is to explain composition. This point is equally valid both for thin accounts as well as for rich accounts that also purport to draw a boundary between lexical meaning and world knowledge. But the problem of how to draw the distinction, and how to integrate semantic and conceptual knowledge, arises even if one is overly restrictive as to the goals of semantic theory. According to various authors, semantics should not be in the business of explaining how truth conditions are obtained; it should explain only that part of meaning that affects grammar, as this is the part of meaning that can be considered part of language proper, i.e. part of the language faculty (see Pietroski 2005, 2017; Levin \& Rappaport Hovav 2011; Yalcin 2014; Collins 2017). What does not affect grammar is not semantic but conceptual.

There has to be such a semantics, it is claimed, because some semantic features (+AGENT, and so on) have an impact on the generative machinery of language. Thus, the dative alternation John gave Sue a book/John gave a book to Sue is possible only if John and Sue can be agent and possessor, respectively (John gave the library a book is not correct, unless library is understood as a group of people). The standard account of the causative alternation (John broke the glass/The glass broke) relies on break being a change-of-state verb, etc. We do not want to dispute that there may be semantic features that have a regular impact on grammar. What we find suspicious is the claim that these features are not part of a larger conceptual, or at any rate, semantically richer, system. If these features were language-internal, it would be difficult to explain how they interact with features that belong to the conceptual system in a way that grammar itself is affected by the interaction. Thus, the following cases exemplify how the typical grammatical behavior of a verb can be affected by the internal and/or the external argument that it takes:

(7) (a) John broke the law.

(b) *The law broke. 
(8) (a) The bank cut its interest rates.

(b) *The bank cut at its interest rates.

(9) (a) *The farmer blossomed the fruit trees.

(b) Early summer heat blossomed fruit trees across the valley.

(10) (a) The days lengthened.

(b) *The skirt lengthened.

(11) (a) John cut the rope.

(b) The rope cut.

(12) (a) The boy is sitting (in the room).

(b) The cups are sitting (*in the cupboard).

Example (7), for instance, shows that the causative alternation is not universal. Examples (9) and (10) show that anticausatives also depend on external arguments. As Levin \& Rappaport Hovav (2013: 58) themselves put it, 'the conditions allowing an anticausative use of a verb are not determined purely by its lexical properties, but also depend on properties of the event described in a sentence with the verb'. Example (8) shows the same kind of thing with respect to the conative alternation. Example (11) should be impossible given that cut doesn't enter into the inchoative alternation. However, the rope cut seems to be acceptable (see Levin \& Rappaport Hovav 2013), and at least its equivalent in Spanish (la cuerda se cortó 'the rope cut') is perfectly fine, whereas cortar 'cut' is generally as bad in intransitive constructions as cut is. Examples (9), (10) and (12) show that knowledge about what external arguments denote also affects grammaticality.

These examples show that one should take into account features of the internal and external arguments to explain the data that these thin semanticists assume semantics has to explain. The question then is how many features, and where such features are possibly located. Apparently, it is facts about laws, interest rates, ropes, meteorological events, etc., i.e. world knowledge that explains that we accept or do not accept some alternations. Taking into account that laws do not break but some other abstract entities do break (e.g. friendships), we may need a rich type-theory or a rich meanings/conceptual knowledge approach in the end to be able to explain how certain grammatical patterns do or do not hold. That is, even this kind of semantics faces demarcation problems.

\section{Conclusion}

The main goal of this paper was to show that there are many phenomena that pertain to the construction of truth-conditional compounds that follow characteristic patterns, and whose explanation requires appealing to knowledge structures organized in specific ways. We have reviewed a number of phenomena, ranging from non-homogenous modification and privative modification to polysemy and 
co-predication, which indicate that knowledge structures do play a role in obtaining truth conditions. After that, we have shown that several extant accounts that invoke rich lexical meanings to explain such phenomena face problems related to inflexibility and lack of predictive power. We have reviewed different ways in which one might react to such problems as regards lexical meanings: go richer, go moderately richer, go thinner, and go moderately thinner. On the face of it, it looks like moderate positions are unstable, given the apparent lack of a clear cutoff point between the semantic and the conceptual, but also that a very thin view and a very rich view may turn out to be indistinguishable in the long run. As far as we can see, the most pressing open questions concern this last issue: Can there be a principled semantic/world knowledge distinction? Where could it be drawn: at some upper level (e.g. enriched qualia structures) or at some basic level (e.g. constraints)? How do parsimony considerations affect these two distinct approaches? A thin meanings approach to lexical meaning seems postulates intermediate representations whose role is not clear in the interpretive process, while a rich meanings approach seems to duplicate representations: the same representations that are stored in the lexicon would form part of conceptual representations. Both types of parsimony problems would be solved by assuming a direct relation between word forms and (parts of) conceptual or world knowledge, leading to a view that has been attributed to Chomsky (e.g. by Katz 1980) in which there is just syntax and encyclopedic knowledge. The question thus becomes or perhaps persists: Do we actually need a semantic/world knowledge distinction to prevent the compositional machinery from collapsing?

\section{REFERENCES}

Arapinis, Alexandra \& Laure Vieu. 2015. A plea for complex categories in ontologies. Applied Ontology 10, 285-296.

Asher, Nicholas. 2011. Lexical meaning in context. Cambridge: Cambridge University Press.

Asher, Nicholas. 2015. Types, meanings and coercions in lexical semantics. Lingua 157, 66-82.

Atlas, Jay David \& Stephen C. Levinson. 1981. H-clefts, informativeness, and logical form: Radical pragmatics. In Peter Cole (ed.), Radical pragmatics, 1-61. New York: Academic Press.

Baggio, Giosuè, Michiel van Lambalgen \& Peter Hagoort. 2012. The processing consequences of compositionality. In Markus Werning, Wolfram Hinzen \& Edouard Machery (eds.), The Oxford handbook of compositionality, 655-672. New York: Oxford University Press.

Baker, Lynn R. 2000. Persons and bodies: A constitution view. Cambridge: Cambridge University Press.

Bierwisch, Manfred \& Robert Schreuder. 1992. From concepts to lexical items. Cognition 42, $23-60$.

Blutner, Reinhard. 1995. Prototypen und kognitive Semantik. In Gisela Harras (ed.), Die Ordnung der Worter, 227-270. Berlin: de Gruyter.

Blutner, Reinhard. 1998. Lexical pragmatics. Journal of Semantics 15.2 115-162.

Blutner, Reinhard. 2004. Pragmatics and the lexicon. In Laurence R. Horn \& Gregory Ward (eds.), Handbook of pragmatics, 488-514. Oxford: Blackwell.

Bücking, Sebastian \& Claudia Maienborn. 2019. Coercion by modification: The adaptive capacities of event-sensitive adnominal modifiers. Semantics and Pragmatics 12, article 9. http://dx.doi.org/10. 3765/sp.12.9.

Carston, Robyn. 2002. Thoughts and utterances. London: Blackwell.

Carston, Robyn. 2012. Word meaning and concept expressed. The Linguistic Review 29, 607-623.

Carston, Robyn. 2016. The heterogeneity of procedural meaning. Lingua 175, 154-166 
Carston, Robyn. 2019. Ad hoc concepts, polysemy and the lexicon. In Kate Scott, Billy Clark \& Robyn Carston (eds.), Relevance, pragmatics and interpretation, 150-162. Cambridge: Cambridge University Press.

Chatzikyriakidis, Stergios \& Zhaohui Luo. 2017. Adjectival and adverbial modification: The view from modern type theories. Journal of Logic, Language and Information 26.1, 45-88.

Chomsky, Noam. 2000. New horizons in the study of language and mind. Cambridge: Cambridge University Press.

Collins, John. 2017. The copredication argument. Inquiry 60, 675-702.

Cruse, Alan. 2004a. Meaning in language: An introduction to semantics and pragmatics. Oxford: Oxford University Press.

Cruse, Alan. 2004b. Lexical facets and metonymy. Ilha do Desterro: A Journal of English Language, Literatures in English and Cultural Studies 47, 73-96.

de Almeida, Roberto G. \& Veena D. Dwivedi. 2008. Coercion without lexical decomposition: Type-shifting effects revisited. Canadian Journal of Linguistics 53.2/3, 301-326.

Deane, Paul D. 1988. Polysemy and cognition. Lingua 75, 325-361.

Del Pinal, Guillermo. 2015. Dual content semantics, privative adjectives, and dynamic compositionality. Semantics and Pragmatics 8.7, 1-53.

Del Pinal, Guillermo. 2017. Meaning, modulation, and context: A multidimensional semantics for truthconditional pragmatics. Linguistics and Philosophy 41.2, 165-207.

Dölling, Johannes. 2003. Flexibility in adverbal modification: Reinterpretation as contextual enrichment. In Ewald Lang, Claudia Maienborn \& Cathrine Fabricius-Hansen (eds.), Modifying adjuncts, 511-552. Berlin \& New York: de Gruyter.

Dölling, Johannes. 2005. Semantische Form und pragmatische Anreicherung: Situationsausdrücke in der Äußerungsinterpretation. Zeitschrift für Sprachwissenschaft 24.2, 159-225.

Dölling, Johannes. 2014. Aspectual coercion and eventuality structure. In Klaus Robering (ed.), Events, arguments, and aspects: Topics in the semantics of verbs, 189-226. Amsterdam \& Philadelphia, PA: John Benjamins.

Evans, Vyvyan. 2009. How words mean: Lexical concepts, cognitive models and meaning construction. Oxford: Oxford University Press.

Falkum, Ingrid L. 2011. The semantics and pragmatics of polysemy: A relevance-theoretic account. Ph.D. thesis, University College London.

Falkum, Ingrid L. 2015. The how and why of polysemy: A pragmatic account. Lingua 157, 83-99.

Falkum, Ingrid L. 2017. The lexical pragmatics of count-mass polysemy. Semantics and Pragmatics 10, article 20. http://dx.doi.org/10.3765/sp.10.20.

Fodor Jerry \& Ernest Lepore. 1998. The emptiness of the lexicon: Reflections on James Pustejovsky's The generative lexicon. Linguistic Inquiry 29.2, 269-288.

Foraker, Stephani \& Gregory L. Murphy. 2012. Polysemy in sentence comprehension: Effects of meaning dominance. Journal of Memory and Language 67, 407-425.

Fraser, Katherine. 2018. Polysemous posture in English: A case study of non-literal meaning. In Alexandra A. Spalek \& Matthew Gotham (eds.), Approaches to coercion and polysemy: Special issue of Oslo Studies in Language 10.2, 9-28.

Frisson, Steven. 2009. Semantic underspecification in language processing. Language and Linguistics Compass 3.1, 111-127.

Frisson, Steven. 2015. About bound and scary books: The processing of book polysemies. Lingua 157, 17-35.

Frisson, Steven \& Lyn Frazier. 2005. Carving up word meaning: Portioning and grinding. Journal of Memory and Language 53, 277-291.

Giora, Rachel. 2008. Is metaphor unique? In Raymond W. Gibbs (ed.), The Cambridge handbook of metaphor and thought, 143-160. New York: Cambridge University Press.

Goldschmidt, Anja. 2018. Hitting playfully but hard: Conceptual effects of verb-adverb modification in the domain of force. Ph.D. dissertation, Utrecht University.

Gotham, Matthew. 2017. Composing criteria of individuation in copredication. Journal of Semantics 34, 333-371.

Hagoort Peter, Giosuè Baggio \& Roel Willems. 2009. Semantic unification. In Michael S. Gazzaniga (ed.), The cognitive neurosciences, 4th edn., 819-36. Cambridge, MA: MIT Press.

Hagoort, Peter, Lea Hald, Marcel Bastiaansen \& Karl M. Petersson. 2004. Integration of word meaning and world knowledge in language comprehension. Science 304, 438-441. 


\section{LOTTE HOGEWEG \& AGUSTIN VICENTE}

Hansen, Nathaniel. 2011. Color adjectives and radical contextualism. Linguistics and Philosophy 34, 201-221.

Hogeweg, Lotte. 2012. Rich lexical representations and conflicting features. International Review of Pragmatics 4, 209-231.

Hogeweg, Lotte. 2019. Suppression in interpreting adjective noun combinations and the nature of the lexicon. Journal of Semantics 36.4, 721-751.

Jackendoff, Ray. 1989. What is a concept that a person may grasp it? Mind and Language 4, 68-102.

Jackendoff, Ray. 2002. Foundations of language: Brain, meaning, grammar, evolution. Oxford \& New York: Oxford University Press.

Katz, Jerrold. 1980. Chomsky on meaning. Language 56, 1-41.

Klepousniotou, Ekaterini, Debra Titone \& Carolina Romero. 2008. Making sense of word senses: The comprehension of polysemy depends on sense overlap. Journal of Experimental Psychology: Learning, Memory, and Cognition 34.6, 1534-1443.

Levin, Beth \& Malka Rappaport Hovav. 2011. Lexical conceptual structure. In Klaus von Heusinger, Claudia Maienborn \& Paul Portner (eds.), Semantics: An international handbook of natural language meaning, vol. I, 420-440. Berlin: De Gruyter Mouton.

Levin, Beth \& Malka Rappaport Hovav. 2013. Lexicalized meaning and manner/result complementarity. In Arsenijević, Gehrke \& Marín (eds.), Subatomic semantics of event predicates, 49-70. Dordrecht: Springer.

Liebesman, David \& Ofra Magidor. 2017. Co-predication and property inheritance. Philosophical Issues 27, 131-166.

MacGregor, Lucy J., Jennifer Bouwsema \& Ekaterini Klepousniotou. 2015. Sustained meaning activation for polysemous but not homonymous words: Evidence from EEG. Neuropsychologia 68, $126-138$.

McConnell-Ginet, Sally. 1982. Adverbs and logical form: A linguistically realistic theory. Language 58.1, 144-184.

McNally, Louise. 2005. Lexical representation and modification within the noun phrase. Recherches Linguistiques de Vincennes 34, 191-206.

McNally, Louise \& Gemma Boleda. 2004. Relational adjectives as properties of kinds. In Olivier Bonami \& Patricia Cabredo Hofherr (eds.), Empirical Issues in Syntax and Semantics 5, 179-196.

McNally, Louise \& Gemma Boleda. 2017. Conceptual vs. referential affordance in concept composition. In Yoad Winter \& James Hampton (eds.), Compositionality and concepts in linguistics and psychology, 245-267. Cham: Springer.

Moravcsik, Julius M. 1975. Aitia as Generative Factor in Aristotle's Philosophy. Dialogue 14, 622-638.

Murphy, Gregory. 2002. The big book of concepts. Cambridge, MA: MIT Press.

Ortega-Andrés, Marina \& Agustín Vicente. 2019. Polysemy and co-predication. Glossa: A Journal of General Linguistics 4.1, 1. doi: http://doi.org/10.5334/gjg1.564.

Partee, Barbara H. 2010. Privative adjectives: Subsective plus coercion. In Rainer Bäuerle, Uwe Reyle \& Thomas Ede Zimmermann (eds.), Presuppositions and discourse: Essays offered to Hans Kamp, 273-285. Bingley: Emerald.

Pietroski, Paul. 2005. Meaning before truth. In Gerhard Preyer \& Georg Peters (eds.), Contextualism in philosophy, 253-300. Oxford: Oxford University Press.

Pietroski, Paul. 2017. Semantic internalism. In James McGilvray (ed.), The Cambridge companion to Chomsky, 196-216. Cambridge: Cambridge University Press.

Pustejovsky, James. 1995. The generative lexicon. Cambridge, MA: MIT Press.

Recanati, François. 2004. Literal meaning. Cambridge: Cambridge University Press.

Recanati, François. 2010. Truth-conditional pragmatics. Oxford: Oxford University Press.

Rothschild, Daniel \& Gabriel Segal, 2009. Indexical predicates. Mind \& Language 24, 467-493.

Schumacher, Petra B. 2013. When combinatorial processing results in reconceptualization: Towards a new approach of compositionality. Frontiers in Psychology 4, 677.

Sperber, Dan \& Deirdre Wilson. 1995. Relevance: Communication and cognition, 2nd edn. Oxford: Blackwell.

Travis, Charles. 1996. Meaning's role in truth. Mind 105, 451-466.

Travis, Charles. 2008. Occasion-sensitivity. Oxford: Oxford University Press.

Vicente, Agustin. 2012. On Travis cases. Linguistics and Philosophy 35, 3-19.

Vicente, Agustin. 2015. The green leaves and the expert: Polysemy and truth-conditional variability. Lingua 157, 54-65. 


\section{THE LEXICON AND RICH LEXICAL MEANINGS}

Vicente, Agustin. 2018. Polysemy and word meaning: An account of lexical meaning for different kinds of content words. Philosophical Studies 175.4, 947-968.

Vicente, Agustín. 2019. Chomskyan arguments against truth-conditional semantics based on variability and co-predication. Erkenn. https://doi.org/10.1007/s10670-019-00138-X

Vicente, Agustin \& Ingrid L. Falkum. 2017. Polysemy. In Mark Aronoff (ed.), Oxford research encyclopedia of linguistics, https://oxfordre.com/linguistics/view/10.1093/acrefore/9780199384655.001.0001/ acrefore-9780199384655-e-325?rskey=KdMAuF\&result=1. New York: Oxford University Press.

Wittgenstein, Ludwig. 1953. Philosophical investigations. Oxford: Blackwell.

Wolff, Phillip. 2007. Representing causation. Journal of Experimental Psychology: General 136.1, 82-111.

Yalcin, Seth. 2014. Semantics and metasemantics in the context of generative grammar. In Alexis Burgess \& Brett Sherman (eds.), New essays in metasemantics, 17-54. New York: Oxford University Press.

Zarcone, Alessandra. 2014. Event knowledge and models of logical metonymy interpretation. Ph.D. dissertation, Universität Stuttgart.

Zeevat, Henk, Scott Grimm, Lotte Hogeweg, Sander Lestrade \& Elizabeth Allyn Smith. 2017. Representing the lexicon: Identifying meaning in use via overspecification. In Kata Balogh \& Wiebke Petersen (eds.), Bridging formal and conceptual semantics: Selected papers of BRIDGE-14, 153-186. Düsseldorf: Düsseldorf University Press.

Zwarts, Joost \& Yoad Winter. 2000. Vector space semantics: A model-theoretic analysis of locative prepositions. Journal of Logic, Language and Information 9.2, 171-213.

Authors' addresses: (Hogeweg)

Centre for Language studies, Radboud University, Erasmusplein 1,

6525 HT Nijmegen, Netherlands

l.hogeweg@let.ru.nl

(Vicente)

Research Centre Micaela Portilla, Justo Vélez de Elorriaga 1, 01006, Vitoria-Gasteiz, Spain

agustin.vicente@ehu.eus 